\title{
ANATOMIA DO LENHO DE MIMOSA ADPRESSA HOOK. \& ARN. (FABACEAE - CAESALPINIOIDEAE) ${ }^{1}$
}

\section{PAULO FERNANDO DOS SANTOS MACHADO² JOSÉ NEWTON CARDOSO MARCHIORI ${ }^{3}$}

\section{RESUMO}

A estrutura microscópica da madeira de Mimosa adpressa é descrita com base em material do Rio Grande do Sul, salientando-se os seguintes caracteres anatômicos: anéis de crescimento distintos; porosidade difusa; poros solitários e em múltiplos radiais; placas de perfuração simples; parênquima axial estratificado, em plano tangencial; raios heterogêneos, de até 4 células de largura, com células procumbentes, quadradas e eretas; e fibras libriformes não septadas.

Palavras-chave: anatomia da madeira, Caesalpinioideae, Mimosa adpressa, Fabaceae, subsérie Obstrigosae.

\section{ABSTRACT}

[Wood anatomy of Mimosa adpressa Hook. \& Arn. (Fabaceae - Caesalpinioideae].

The wood microscopic features of Mimosa adpressa is described, based on material from Rio Grande do Sul State, Brazil, being highlighted: distinct growth rings; diffuse porous wood; solitary and radial multiple vessels; simple perforation plates; stratified axial parenchyma; heterogeneous rays, up to 4 cells wide and with procumbent, square and upright cells; and libriform non-septate fibers.

Key words: Caesalpinioideae, Fabaceae, Mimosa adpressa, subseries Obstrigosae, wood anatomy.

\section{INTRODUÇÃO E REVISÃO DE LITERATU- RA}

Arbusto lenhoso de até $1,5 \mathrm{~m}$ de altura e caules subcilíndricos, por vezes avermelhados, $M i$ mosa adpressa Hook. \& Arn. distribui-se pela Mesopotâmia argentina, Uruguai e Rio Grande do Sul, habitando, preferencialmente, locais muito secos e pedregosos (Rambo, 1966). De sua morfologia, destaca-se a presença de acúleos infraestipulares e internodais de 5-6 mm de comprimento, retos ou ascendentes e de base larga, os capítulos globosos, sésseis ou subsésseis, as flores tetrâmeras com quatro estames, e as setas retrorsas, adpressas e de base alargada (Izaguirre \& Beyhaut, 2003). A forma das setas justifica a inserção da espécie na subsérie

1 Recebido em 19-5-2017 e aceito para publicação em 05-08-2017.

2 Engenheiro Florestal, doutorando do Programa de PósGraduação em Engenharia Florestal, Universidade Federal de Santa Maria. Santa Maria, RS, Brasil. barcasole@gmail.com

3 Engenheiro Florestal, Dr. Bolsista de Produtividade em Pesquisa (CNPq - Brasil). Professor Titular do Departamento de Ciências Florestais, Universidade Federal de Santa Maria. marchiori@pq.cnpq.br
Obstrigosae (Benth.) Barneby, da série Mimo$s a \mathrm{~L}$., ao passo que os pedúnculos, extremamente curtos (até 2,5 mm) ou ausentes, permitem distinguir a espécie de outras da referida subsérie (Barneby, 1991).

O lenho de Mimosa adpressa ainda não foi atomicamente investigado a partir de amostras do Rio Grande do Sul. Com base em material argentino, Cozzo (1949) refere, para a mesma, a ocorrência de estratificação incompleta e uniforme, embora pouco visível pela escassez de séries parenquimáticas. Em artigo posterior, Cozzo (1951) relacionou para Mimosa adpressa: anéis de crescimento visíveis; porosidade difusa; vasos ovais, solitários e em curtos múltiplos de 2 ; elementos vasculares muito curtos, com apêndices igualmente curtos, mas desprovidos de tiloses e espessamentos espiralados; placas de perfuração simples; pontoações intervasculares alternas, de abertura inclusa; pontoações raiovasculares e parênquimo-vasculares, semelhantes às intervasculares; traqueídeos vasicêntricos, escassos; parênquima axial escassamente paratraqueal e difuso, principalmente fusiforme; raios tetraseriados, em sua maioria, com poucos bi e 5-seriados, com 35 (8-80) células de 
altura; raios heterogêneos, com células envolventes pouco destacadas; fibras muito curtas, com pontoações "apenas areoladas"; e presença de cristais, em células marginais de raio e em fibras adjacentes.

A respeito da estratificação, Cozzo (1949, 1951) cita o caráter apenas para Mimosa adpressa e M. scabrella, dentre onze espécies investigadas. No tocante à subsérie Obstrigosae (Benth.) Barneby, salienta-se que Machado \& Marchiori (2016) não registraram o caráter nos lenhos de Mimosa parvipinna Benth. e Mimosa ramulosa Benth.

\section{MATERIAL E MÉTODOS}

$\mathrm{O}$ material investigado consiste em uma amostra de madeira e respectiva exsicata botânica, conservados na Xiloteca e Herbário do Departamento de Ciências Florestais da Universidade Federal de Santa Maria com os seguintes registros: HDCF 717; Mimosa adpressa Hook. \& Arn.; nome comum: rama-negra; Leg.: Marchiori, J.N.C., 30-09-1982, Alegrete, BR 290 km 523, próximo ao rio Inhanduí; arbustos semi-esféricos.

Do material lenhoso foram preparados três corpos-de-prova com dimensão aproximada de $1 \times 2 \times 3 \mathrm{~cm}$, orientados para a obtenção de cortes anatômicos nos planos transversal, longitudinal radial e longitudinal tangencial. Os corpos-deprova foram fervidos em água até a expulsão completa do ar e, na sequência, seccionados em micrótomo de deslize, modelo American Optical, no Laboratório de Anatomia da Madeira da Universidade Federal do Paraná. Os cortes foram coloridos com acridina-vermelha, crisoidina e azul-de-astra (Dujardin, 1964) e, na sequência, desidratados em série alcoólica ascendente até álcool absoluto, passaram por xilol e, finalmente, montados em lâminas permanentes, com resina Entellan.

Um quarto bloquinho foi também preparado, com vistas à maceração. Para isso, foram obtidos finos palitinhos com o uso de formão. Os palitinhos foram reunidos em tubo-de-ensaio, fervidos em água por 8 horas e submetidos a dois banhos com solução de Jeffrey (Freund, 1970), por período de 24 horas cada.

A descrição microscópica baseou-se nas recomendações da IAWA (Wheeler et al., 1989). No caso da percentagem de tecidos, foram feitas 600 determinações ao acaso, usando-se um contador de células, conforme proposto por Marchiori (1980). A frequência de poros foi determinada a partir de um quadrado de área conhecida, superposto, repetidas vezes, a fotomicrografias da madeira em plano transversal.

As medições da estrutura anatômica foram realizadas em microscópio Carl Zeiss, no Laboratório de Anatomia da Madeira da Universidade Federal de Santa Maria (campus sede). As imagens que ilustram o texto foram tomadas em fotomicroscópio Leica, modelo DM 2000, equipado com câmera digital Leica, modelo DFC 295, no Laboratório de Botânica Estrutural do Departamento de Biologia (Centro de Ciências Naturais e Exatas), da Universidade Federal de Santa Maria.

\section{DESCRIÇÃO DA MADEIRA}

Anéis de crescimento: distintos, marcados por camada com 2-3 fibras radialmente estreitas e de paredes mais espessas, no lenho tardio (Figura 1A,B).

Vasos: muito numerosos $(79 \pm 14(54-100)$ poros $/ \mathrm{mm}^{2}$ ), ocupando $11 \pm 2,9 \%$ do volume da madeira. Porosidade difusa. Poros em múltiplos radiais $(53 \%)$, solitários $(34 \%)$, com poucos racemiformes $(13 \%)$; circulares ou ovais (43 \pm $9(20-58) \mu \mathrm{m})$ e de paredes espessas $(3,8 \pm 1$ $(2,5-6,3) \mu \mathrm{m}$ ) (Figura 1A,B). Elementos vasculares curtos $(188 \pm 37(90-250) \mu \mathrm{m})$, com placas de perfuração simples, obliquas ou transversais ao vaso (Figura 1D); apêndices ausentes ou, então, curtos (18 $\pm 13(10-40) \mu \mathrm{m})$, geralmente em uma extremidade. Pontoações intervasculares pequenas e arredondadas (5,2 \pm $0,7(3,6-6,2) \mu \mathrm{m})$, alternas e ornamentadas, com abertura lenticular, horizontal, inclusa. Pontoações raio-vasculares, semelhantes às intervasculares, embora menores $(4,2 \pm 0,6$ (3,6 
- 5,2) $\mu \mathrm{m})$. Espessamentos espiralados, ausentes. Conteúdos, abundantes no cerne.

Parênquima axial: paratraqueal escasso ( $\mathrm{Fi}-$ gura 1A, B), estratificado (Figura 1E, F), representando $2 \pm 1,7 \%$ do volume da madeira. Células fusiformes de $198 \pm 37$ (125-250) $\mu \mathrm{m}$ de altura (Figura 1E, F). Séries parenquimáticas de $211 \pm 51$ (150-400) $\mu \mathrm{m}$ de altura, com 2-4 células (Figura 1E, F). Cristais romboédricos de 8,8 $\pm 3,2$ (4-15) $\mu \mathrm{m}$, em câmaras.

Raios: numerosos ( $8 \pm 1,6(5-11)$ raios $/ \mathrm{mm})$, ocupando $18 \pm 3 \%$ do volume da madeira. Os unisseriados (3\%), de $14 \pm 2$ (11-18) $\mu \mathrm{m}$ e 2-8 células de altura, compostos de células procumbentes e quadradas. Os multisseriados, tetrasseriados (42\%), trisseriados (31\%), menos comumente bisseriados (11\%) e com mais de 4 células de largura (13\%); de $308 \pm 91$ (175-300) $\mu \mathrm{m}$ e 6-24 células de altura, formados por uma mistura de células procumbentes, quadradas e curtamente eretas (Figura 1C, D). Células radiais de contorno arredondado, em plano tangencial (Figura 1E, F); células envolventes, células radiais de paredes disjuntas e células perfuradas, ausentes. Raios fusionados, raios agregados e conteúdos, presentes. Cristais romboédricos, presentes em células quadradas.

Fibras: libriformes, não septadas (Figura 1CE), curtas $(688 \pm 125(450-1030) \mu \mathrm{m})$, com 15 $\pm 2,8(10-22) \mu \mathrm{m}$ de largura e paredes finas a espessas 3,2 $\pm 0,6(1,9-3,8) \mu \mathrm{m}$, ocupando $69 \pm$ $5 \%$ do volume da madeira (Figura 1B). Fibras gelatinosas, abundantes. Espessamentos espiralados, ausentes.

Outros caracteres: variantes cambiais, tubos laticíferos e taniníferos, canais intercelulares, células oleíferas, células mucilaginosas e máculas medulares, ausentes. Estratificação parcial das células de parênquima axial, em plano tangencial (Figura 1E, F), embora pouco evidente devido à escassa abundância do referido tecido no lenho.

\section{ANÁLISE DA ESTRUTURA ANATÔMICA}

O lenho de Mimosa adpressa apresenta os seguintes caracteres anatômicos de ampla ocorrência em Leguminosae (= Fabaceae), segundo
Record \& Hess (1949) e Metcalfe \& Chalk (1972): placas de perfuração simples; elementos vasculares curtos; pontoações intervasculares alternas e ornamentadas; parênquima paratraqueal; e fibras libriformes. A par destes caracteres anatômicos, verifica-se uma considerável diversidade estrutural entre as subfamílias e gêneros de Fabaceae, tema que segue à espera de estudos mais aprofundados no que diz respeito à presença (ou ausência) dos distintos caracteres e o valor filogenético dos mesmos.

A respeito da taxonomia, cabe salientar que os gêneros de Mimosoideae foram recentemente incorporados a Caesalpinioideae, a qual, por sua vez, deu origem a novas subfamílias, mediante desmembramento. Tradicionalmente, reconhecia-se o lenho das Caesalpinioideae como o mais primitivo das Leguminosae (BarettaKuipers, 1981), e que a evolução do xilema secundário seguiu dois rumos distintos a partir da referida subfamília: em direção às Mimosoideae, pela especialização dos raios, e em direção às Papilionoideae, pela estratificação de todos os elementos.

A estrutura anatômica de Mimosa adpressa, presentemente descrita, contesta as tendências apontadas pela referida anatomista, ao mesmo tempo que reforça tanto as conclusões de Cozzo (1951) para o gênero em estudo, como, até mesmo, a recente incorporação das Mimosoideae à subfamília Caesalpinioideae.

Apesar das numerosas espécies de Mimosa e de outros gêneros de Mimosoideae que apresentam raios homogêneos, não são raras as espécies com raios nitidamente heterogêneos, à semelhança do observado em Mimosa adpressa.

Em investigação anatômica do lenho de treze espécies argentinas, incluindo Mimosa adpressa, Cozzo (1951) observou uma ampla variação anatômica no grupo, salientando a inexistência de um traço anatômico "comum que as enlace". "Estruturalmente heterogêneo", o autor concluiu que a variabilidade por ele observada em Mimosa sp. corresponde ao verificado em toda a subfamília Mimosoideae. Sob este ponto, salienta-se, para o gênero, a ocor- 

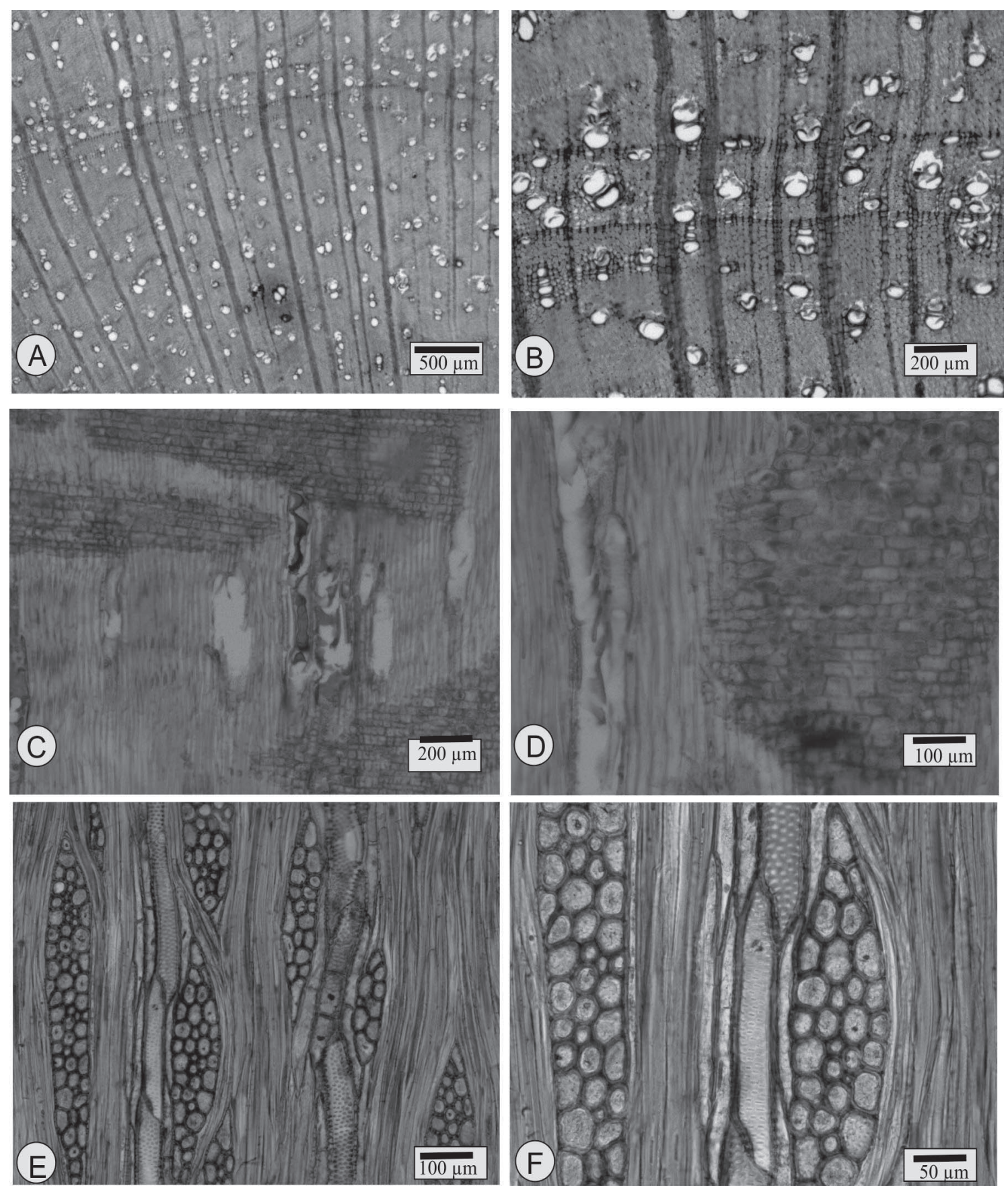

FIGURA 1 - Aspectos anatômicos do lenho de Mimosa adpressa. A, B - Porosidade difusa, poros solitários e em múltiplos radiais, e anéis de crescimento distintos (seção transversal). C - Raios heterogêneos, vasos e fibras libriformes não septadas (seção longitudinal radial). D - Mesmo plano anatômico e detalhes da foto anterior, salientando uma placa de perfuração simples. E, F - Cortes longitudinais tangenciais da madeira, em distintos aumentos, salientando raios 34-seriados, fibras libriformes não septadas e estratificação do parênquima axial. 
rência (ou não) de estratificação, bem como a grande variabilidade na estrutura radial, havendo tanto espécies com raios homogêneos, compostos, inteiramente, de células procumbentes, como em Mimosa cruenta Benth. (Marchiori, 1985), Mimosa uruguensis Hook. \& Arn. (Marchiori, 1996), Mimosa barnebiana Fortunato \& Tressens e Mimosa bifurca Benth. (Machado et al., 2016), pertencentes à série Stipellares Benth., como raios nitidamente heterogêneos, caso da espécie em estudo, de $M i$ mosa parvipinna Benth. e de Mimosa ramulosa Benth., vinculadas à subsérie Obstrigosae (Benth.) Barneby (Machado \& Marchiori, 2016).

Caráter reconhecidamente primitivo, a heterogeneidade dos raios, segundo BarettaKuipers (1981), é traço anatômico típico de Caesalpinioideae. A observação do mesmo em Mimosa adpressa e em outras espécies do gênero, por conseguinte, depõe, contrariamente, ao reconhecimento das Mimosoideae como subfamília distinta. De fato: a diversidade estrutural verificada no gênero Mimosa, além de corresponder ao observado no conjunto das Mimosoideae, como observado, inicialmente, por Cozzo (1951), também inviabiliza o uso de argumentos anatômicos para contestar a inclusão das Mimosoideae na subfamília Caesalpinioideae.

No caso da estratificação do parênquima axial, esse caráter, amplamente reconhecido como "especializado", também consta, na literatura anatômica, para Mimosa scabrella (Cozzo, 1949; Mainieri, 1973; Mainieri \& Chimello, 1989; Marchiori, 1980, 1995; Marchiori et al., 2009; Paraná, 1979; Richter \& Charvet, 1973) e Mimosa taimbensis (Machado \& Marchiori, 2017), espécies vinculadas à seção Calothamnos Barneby.

\section{REFERÊNCIAS BIBLIOGRÁFICAS}

BARETTA-KUIPERS, T. Wood anatomy of Leguminosae: its relevance to Taxonomy. In: POLHILL, R.M.; RAVEN, P.H. Advances in Le- gume Systematics. Kew: Royal Botanic Gardens, 1981. p. 677-715.

BARNEBY, R.C. Sensitivae Censitae. A description of the Genus Mimosa Linnaeus (Mimosaceae) in the New World. Memoirs of the New York Botanical Garden, New York, v. 65, p. 1-835, 1991.

COZZO, D. Estructura leñosa estratificada no registrada en géneros de Leguminosas argentinas. Lilloa, Tucumán, v. 16, p. 63-95, 1949.

COZZO, D. Anatomia del leño secundário de las Leguminosas Mimosoideas y Caesalpinioideas argentinas silvestres y cultivadas. Revista del Instituto Nacional de Investigación de las Ciencias Naturales, Ciencias Botánicas, Buenos Aires, v. 2, n. 2, p. 63-290, 1951.

DUJARDIN, E.P. Eine neue Holz-Zellulosenfaerbung. Mikrokosmos, n. 53, p. 94, 1964.

FREUND, H. Handbuch der Mikroskopie in der Technik. Frankfurt: Umsham Verlag, 1970. 375 p.

IZAGUIRRE, P.; BEYHAUT, R. Las Leguminosas en Uruguay. Montevideo: Hemisfério Sur, 2003. $301 \mathrm{p}$.

MACHADO, P.F. dos S.: MARCHIORI, J.N.C. Anatomia do lenho de duas espécies sul-brasileiras do gênero Mimosa L. e subsérie Obstrigosae (Benth.) Barneby. Balduinia, Santa Maria, n. 52, p. 22-29, 2016.

MACHADO, P.F. dos S.; MARCHIORI, J.N.C. Anatomia dos lenhos de Mimosa intricata Benth. e Mimosa taimbensis Burkart (Fabaceae). Balduinia, Santa Maria, n. 57, p. 19-29, 2017.

MACHADO, P.F. dos S.; MARCHIORI, J.N.C.; BALDIN, T. Anatomia da madeira de duas espécies de Mimosa da série Stipellares Benth. Balduinia, Santa Maria, n. 54, p. 1-10, 2016.

MAINIERI, C. Madeiras do litoral sul: estados de São Paulo, Paraná e Santa Catarina - nomenclatura botânica e vulgar, características gerais e usos comuns. São Paulo: Secretaria da Agricultura, 1973. 84p. (Bol. n. 3).

MAINIERI, C.; CHIMELO, J.P. Fichas de características das madeiras brasileiras. São Paulo: IPT, 1989. 418p.

MARCHIORI, J.N.C. Estudo anatômico do xilema secundário e da casca de algumas espécies dos gêneros Acacia e Mimosa, nativas no estado do Rio Grande do Sul. Dissertação (Mestrado em Engenharia Florestal). Curitiba: Universidade Federal do Paraná, 1980. 186 f. 
MARCHIORI, J.N.C. Anatomia da madeira de $M i$ mosa cruenta Benth. (Leguminosae Mimosoideae). Ciência e Natura, Santa Maria, n. 7, p. 73-81, 1985.

MARCHIORI, J.N.C. Anatomia da madeira e casca da bracatinga, Mimosa scabrella Benth. Ciência e Natura, Santa Maria, n. 17, p. 115-132, 1995.

MARCHIORI, J.N.C. Anatomia do xilema secundário de Mimosa uruguensis Hook. \& Arn. Ciência e Natura, S. Maria, n. 18, p. 103-115, 1996.

MARCHIORI, J.N.C.; MUÑIZ, G.I.B. de; SANTOS, S.R. dos. Madeiras do Rio Grande do Sul. 1 Descrição microscópica de 33 espécies nativas. Santa Maria: [s.n.], 2009. 80p.

METCALFE, C.R.; CHALK, L. Anatomy of the Dicotyledons. Oxford: Clarendon Press, 1972. 1500 p.
PARANÁ. Universidade Federal do. Centro de Pesquisas Florestais. Estudo das anternativas, técnicas, econômicas e sociais para o setorflorestal do Paraná. Subprograma Tecnologia. Curitiba, 1979. 335f.

RAMBO, B. Leguminosae riograndenses. Pesquisas, São Leopoldo, n. 23, p. 1-166, 1966. (separata).

RECORD, S.J.; HESS, R.W. Timbers of the New World. New Haven: Yale University Press, 1949. $640 \mathrm{p}$.

RICHTER, H.G.; CHARVET, L.M. Estudo e pesquisa sobre Mimosa scabrella. Floresta, Curitiba, v. 4, n. 2, p. 68-69, 1973.

WHEELER, E.A.; BAAS, P.; GASSON, P.E. IAWA list of microscopic features for hardwood identification. IAWA Bulletin, v. 10, n. 3, p. 218359, 1989. 